\title{
From the Chair: Reaching Out and Growing
}

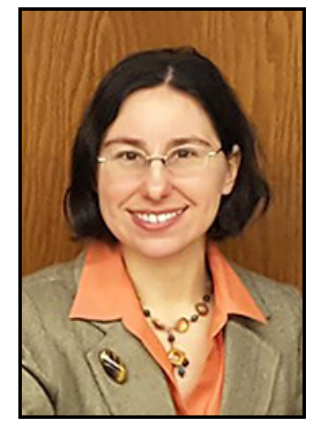

your colleagues.

Midwinter brought us news that ALA is having financial issues, causing Forward Together to hit some speed bumps with ALA Council not expected to vote on the Steering Committee on Organizational Effectiveness (SCOE) recommendations till January 2021. Although Forward Together is slightly stalled, the issues and threat to GODORT remain. GODORT needs to increase membership if we want to remain a round table and be taken seriously by our parent organization.

One option to increase membership is to merge. The Member Update gave us an opportunity to start seriously thinking of a merger with the Map and Geospatial Information Round Table (MAGIRT). Merging should not be seen as just a means to an end, but a logical joining of two round tables with similar interests and concerns. The merger process is slow, and first requires discussion and input from the membership of both organizations. If membership decides to pursue this option, then a vote to merge can be held in 2021 and a merger plan approved in 2022. I believe that with input from our members, we can transform into a stronger organization that maintains the best and most important aspects of both groups. We have a library guide https://godort.libguides.com/GODORT-MAGIRTmerger where you can see where we are in the process, a link to a survey, and other options to share your opinion.

Forward Together is a catalyst, encouraging us to reach out to groups outside of ALA. We are now affiliated with the State Documents Collaborative Group. This group's goals are closely aligned with ours; they are working to raise awareness, preserve and ensure public access to state and local documents.

This year GODORT is also sponsoring the Western States Government Information Virtual Conference. This free, biennial conference started as an economical way for government librarians in six western states, to meet. It has grown since then and remains a wonderful opportunity for government information professionals at all levels.

We will continue to reach out to our members, and anyone interested in government information by offering more virtual options. Our first fully online Midwinter Virtual Meeting in January had strong attendance. This event provided us with valuable experience that will inform our fully virtual Annual conference.

Please stay safe, and healthy.

Susanne Caro (susanne.caro@ndsu.edu), Government Information Librarian

"From the Chair" is licensed under a Creative Commons Attribution 4.0 International License.

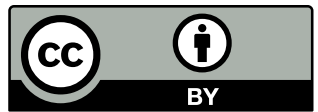

\section{Congratulations to our newly elected GODORT officials}

Chair-elect: Robbie Sittel

Publication Committee Chair-elect: Christopher C. Brown

Bylaws Coordinator: Angela J.A. Kent

Secretary: Kelly Marie Wilson

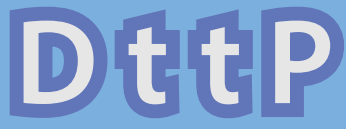

Documents to the People 